\title{
Lactação em Éguas da Raça Mangalarga Marchador: Produção e Composição do Leite e Ganho de Peso dos Potros Lactentes ${ }^{1}$
}

\author{
Edson Mauro Santos ${ }^{2}$, Fernando Queiroz de Almeida ${ }^{3}$, Antônio Assis Vieira ${ }^{4}$, Luís Fernando \\ Batista Pinto ${ }^{5}$, Anderson Corassa ${ }^{5}$, Robson Ricardo Moreira Pimentel ${ }^{5}$, Vinicius Pimentel Silva ${ }^{5}$, \\ Leandro Galzerano ${ }^{6}$
}

\begin{abstract}
RESUMO - Objetivou-se, com este trabalho, avaliar a produção e a composição do leite de éguas Mangalarga Marchador e o ganho de peso dos potros lactentes. A produção de leite foi avaliada em oito éguas, pelo método da pesagem dos potros antes e depois das mamadas, em intervalos de duas horas, em doze observações diárias. A partir do somatório da quantidade de leite produzido nas observações, obteve-se a produção diária de leite. A produção de leite, analisado quanto aos teores de lactose, proteína, gordura e energia, foi avaliada aos 20, 40, 60, 80, 100, 120, 140 e 160 dias da lactação A produção média de leite variou de 9,95 kg/dia no 40o dia a $7,48 \mathrm{~kg} /$ dia no final da lactação. A produção total de leite estimada foi igual a 1405,56 kg. A produção de leite, expressa em percentual do peso vivo (PV) das éguas, variou entre $2,3 \%$ do PV no 20 o dia e 1,8\% do PV no final da lactação, sendo similar às quantidades de leite produzidas nos períodos diurno e noturno. Não foi observado efeito da idade das éguas na produção de leite. O ganho médio diário de peso dos potros ao longo do período de amamentação foi de $0,77 \mathrm{~kg}$, com maiores valores nos meses iniciais do período de amamentação. O leite das éguas apresentou baixas concentrações de proteína, gordura e energia e altas de lactose, além de resposta quadrática decrescente, em função do período da lactação.
\end{abstract}

Palavras-chave: lactação, eqüinos, exigências nutricionais

\section{Lactation in Mangalarga Marchador Mares: Yield production and Composition of Milk, and Weight Gain of Suckling Foals}

\begin{abstract}
This work aims to evaluate yield production and composition of milk of Mangalarga Marchador mares and average weight gain of suckling foals. Milk yield was evaluated in eight mares by the weigh-suck-weigh method, at intervals of two hour, twelve times a day. Daily milk produced was estimated by summing of the twelve observations. Milk yield was performed at 20, 40, 60, 80, $100,120,140$ and 160 days of lactation. The milk was analyzed for lactose, protein, fat and energy concentration. Daily milk production ranged from $9.95 \mathrm{~kg}$ at $40^{\text {th }}$ day to $7.48 \mathrm{~kg}$ no final da lactação (160 th day) Total estimate milk yield during the lactation was 1405.56 $\mathrm{kg}$. Milk yield as a $\% \mathrm{LW}$ of mares ranged from $2.3 \% \mathrm{LW}$ at $20^{\text {th }}$ day to $1.8 \% \mathrm{LW}$ at the end of lactation. Amounts of milk produced during daytime and nighttime was similar and mare age did not affect milk production. Average weight gain of foals during lactation period was $0.77 \mathrm{~kg} /$ day with higher values at first months of lactation period. Milk showed low concentration of protein, fat and energy, high levels of lactose, with a decreasing quadratic response in function of lactation period.
\end{abstract}

Key Words: horse, lactation, nutritional requirements

\section{Introdução}

A fase de amamentação dos potros, com duração aproximada de 180 dias, pode variar em função do manejo do rebanho. É uma das mais importantes na vida do animal, quando a taxa de crescimento é acelerada e suas exigências nutricionais são maiores (Cunha, 1991).
Segundo Saastamoinen (1996), o crescimento de potros durante o primeiro ano é rápido, pois, aos doze meses de idade, $65 \%$ do peso definitivo e cerca de $90 \%$ da altura dos animais adultos são alcançados. Almeida et al. (2000) observaram que potros da raça Mangalarga Marchador apresentam, ao nascimento, o peso vivo equivalente a $8 \%$ do peso vivo do adulto e, aos seis meses de idade, cerca de $38 \%$ do peso vivo

\footnotetext{
${ }^{1}$ Parte da Dissertação do primeiro autor apresentada ao Programa de Pós-graduação em Zootecnia da UFRRJ. Projeto de Pesquisa financiado pela FAPERJ.

2 Discente de Mestrado em Zootecnia - UFRRJ - Seropédica - RJ.

3 Professor Adjunto. Instituto de Veterinária - UFRRJ. Bolsista do CNPq.

Correspondência: DMCV-IV-UFRRJ. BR 465, km 7, Seropédica, RJ. CEP:23890-000.E.mail:falmeida@ufrrj.br

4 Professor Adjunto. DPA-IZ-UFRRJ. BR 465, km7, Seropédica, RJ. CEP:23890-000. E.mail: aassis@ufrrj.br

${ }^{5}$ Graduando em Zootecnia. Bolsista de Iniciação Científica - FAPERJ.

${ }^{6}$ Graduando em Licenciatura em Ciências Agrícolas - UFRRJ. Bolsista de iniciação científica CNPq.
} 
do adulto. Portanto, conhecer a produção e composição de leite é essencial para se estabelecer melhor as exigências nutricionais de potros e éguas durante o período de lactação (Oftedal et al., 1988).

A produção e composição do leite de éguas podem ser influenciadas por vários fatores: idade, ordem de parto, peso vivo das éguas, dieta, condições ambientais e estádio da lactação. Alguns autores observaram aumento da produção de leite de éguas criadas a pasto em resposta à suplementação protéica (Gibbs et al., 1982; Doreau et al., 1991a), enquanto Martin et al. (1992) verificaram que éguas mantidas em pastagens de Cynodon dactylon sem suplementação produziram quantidade de leite equivalente à de éguas mantidas nesta mesma pastagem e recebendo dois quilogramas diários de ração concentrada contendo $24 \%$ de proteína bruta.

A produção de leite varia em função da raça, sendo que as éguas de raças mais pesadas tendem a produzir mais leite que éguas de raças mais leves. Doreau et al. (1991b), avaliando a produção de leite de éguas da raça Bretão Postier, observaram produção máxima de $17,7 \mathrm{~kg} /$ dia, na oitava semana de lactação, enquanto Cabrera et al. (1990), avaliando a produção de leite de éguas Puro Sangue Inglês, obtiveram produção máxima de $14,9 \mathrm{~kg} /$ dia, após o segundo mês de lactação. Entretanto, considerando a produção de leite expressa em percentual do peso vivo, observaram-se valores semelhantes nos dois trabalhos citados, com valores de 2,8 e $3,0 \%$, respectivamente.

A produção de leite das éguas é crescente até atingir o pico, antes do segundo mês de lactação, e decresce constantemente até o final do período de lactação, aos 180 dias aproximadamente (Oftedal et al., 1983; Cabrera et al., 1990; Doreau et al., 1990; Gibbs et al., 1982).

O leite de éguas é pobre em energia ( 425 a 825 $\mathrm{kcal} / \mathrm{kg}$ ), em gordura (1,0 a 1,5\%) e em proteína bruta $(1,89$ a $2,87 \%)$, mas rico em lactose $(6,5$ a $6,6 \%)$ (Pagan \& Hintz, 1988; Gibbs et al., 1982), quando comparado ao leite das demais espécies domésticas. A concentração dos diversos constituintes do leite decresce desde o início do período de lactação, com exceção da lactose, que é crescente no início e decrescente ao final da lactação. Segundo Doreau et al. (1991b), lactose é um fator controlador da pressão osmótica dentro do úbere, o que favorece o enchimento do mesmo.

Este trabalho foi desenvolvido com os objetivos de avaliar a produção e variação dos constituintes do leite analisados (lactose, proteína, gordura e energia) ao longo do período de lactação de éguas da raça Mangalarga Marchador; comparar a produção de leite das éguas nos períodos diurno e noturno; comparar a produção de leite das éguas de duas faixas etárias (de 8 a 11 anos e de 16 a 19 anos); e avaliar o ganho de peso de potros lactentes da raça Mangalarga Marchador, no período de lactação.

\section{Material e Métodos}

O presente experimento foi realizado no Setor de Eqüinocultura do Instituto de Zootecnia da Universidade Federal Rural do Rio de Janeiro, Seropédica, RJ. A região apresenta duas estações distintas, uma seca, que se estende de abril a setembro, e outra quente e chuvosa, que se estende de outubro a março. Dados dos últimos 10 anos mostram precipitação média anual de $1281,7 \mathrm{~mm}$ e temperaturas médias anuais de $29,8^{\circ} \mathrm{C}$ e $20,1^{\circ} \mathrm{C}$, para a máxima e mínima, respectivamente.

Foram utilizadas oito éguas multíparas da raça Mangalarga Marchador do rebanho da UFRRJ, com idade variando entre 8 e 19 anos e peso vivo ao parto de 415 a $440 \mathrm{~kg}$, divididas em dois grupos em função da idade: Grupo I - formado por éguas com idade entre 8 e 11 anos e Grupo II - formado por éguas com idade entre 16 e 19 anos. Os partos ocorreram entre os meses de janeiro e março de 2002. As éguas estavam gestantes de garanhões da raça Mangalarga Marchador e, ao parto, apresentaram escore corporal entre 4,0 e 5,0, segundo metodologia citada por Hennecke et al. (1983).

As éguas foram mantidas em pastagem de capim-estrela (Cynodon nlenfluensis) e, diariamente, no período de 7 às $9 \mathrm{~h}$, eram recolhidas em baias individuais, onde recebiam $2,0 \mathrm{~kg} / \mathrm{animal} /$ dia de ração concentrada. A composição bromatológica da ração concentrada e das amostras de pasto pode ser observada na Tabela 1.

Durante o manejo nutricional das éguas, os potros foram submetidos a manejo de doma racional, visando facilitar o trabalho de pesagem e de avaliação da produção de leite das éguas. Os potros e as éguas foram submetidos ao controle de ecto e endoparasitos utilizando-se a ivermectina, na dose de $200 \mathrm{mg} / \mathrm{kg}$ de peso vivo.

A produção de leite foi avaliada pelo método da pesagem dos potros antes e depois das mamadas, em intervalos de duas horas, adaptado de Gibbs et al.

\section{R. Bras. Zootec., v.34, n.2, p.627-634, 2005}




\begin{tabular}{|c|c|c|}
\hline $\begin{array}{l}\text { Nutriente } \\
\text { Nutrient }\end{array}$ & $\begin{array}{c}\text { Pastagem } \\
\text { Grass }\end{array}$ & $\begin{array}{c}\text { Ração concentrada } \\
\text { Concentrate }\end{array}$ \\
\hline Matéria seca (\%) & 44,6 & 89,9 \\
\hline Dry matter & & \\
\hline $\begin{array}{l}\text { Proteína bruta }(\%) \\
\text { Crude protein }\end{array}$ & 10,4 & 13,6 \\
\hline $\begin{array}{l}\text { Extrato etéreo }(\%) \\
\text { Ether extract }\end{array}$ & 1,7 & 3,9 \\
\hline $\begin{array}{l}\text { Energia bruta }(\mathrm{Mcal} / \mathrm{kg}) \\
\text { Gross energy }\end{array}$ & 4,2 & 4,1 \\
\hline
\end{tabular}

(1982). No dia da avaliação, os procedimentos de pesagem ocorreram por 12 horas (das $7 \mathrm{~h}$ às $7 \mathrm{~h}$ do dia seguinte). Neste método, os potros usaram embornais, que os impediram de mamar e, dessa forma, puderam permanecer junto das éguas, durante o período de avaliação da produção de leite. Os animais foram colocados em piquetes (aproximadamente 0,5 ha) de capim-estrela, com água à vontade $\mathrm{e}$, a cada duas horas, os potros eram levados para baias, onde eram pesados e, em seguida, retiravam-se os embornais. Após um período de aproximadamente 15 minutos de amamentação, o suficiente para que houvesse o esvaziamento do úbere, os potros eram pesados novamente.

A diferença entre a primeira e a segunda pesagens foi considerada a produção de leite no intervalo de duas horas. O somatório das produções de leite dos 12 intervalos durante o dia foi considerado a produção diária de leite. A avaliação da produção de leite foi realizada no 20 을 dia após o parto e em intervalos de 20 dias até o 160 o dia de lactação. Foi definido como período diurno aquele compreendido entre $7 \mathrm{~h}$ e $17 \mathrm{~h}$ e, como período noturno, aquele entre $19 \mathrm{~h}$ e $6 \mathrm{~h}$.

A produção de leite na lactação total foi calculada multiplicando-se a produção diária de leite pelo total de dias do intervalo avaliado e somando-se as produções de todos os intervalos.

$\mathrm{Na}$ avaliação do peso dos potros, utilizou-se uma balança eletrônica com precisão de $50 \mathrm{~g}$. As pesagens dos potros foram procedidas ao nascimento e a cada 20 dias, conforme a descrição da avaliação da produção de leite. As pesagens consideradas na avaliação do ganho de peso dos animais foram as efetuadas às $7 \mathrm{~h}$, nos dias de avaliação da produção de leite das éguas, totalizando nove pesagens, do nascimento aos 160 dias de idade.

As amostras de leite foram coletadas nos dias de avaliação da produção de leite, às 7h, no intuito de evitar diferenças na composição das amostras de leite em decorrência de possíveis alterações ao longo do dia. O procedimento utilizado foi o da ordenha manual, com a presença do potro para induzir a descida do leite. Aproximadamente $100 \mathrm{~mL}$ de leite foram coletados e armazenados a $-18^{\circ} \mathrm{C}$, para posterior análise química.

As amostras da gramínea nas pastagens e da ração concentrada foram analisadas no Laboratório de Bromatologia do Departamento de Nutrição Animal e Pastagens do Instituto de Zootecnia da UFRRJ, quando foram efetuadas as análises de matéria seca (MS), proteína bruta $(\mathrm{PB})$, extrato etéreo (EE), de acordo com os métodos da AOAC (1984). A energia bruta (EB) foi determinada utilizando-se a bomba calorimétrica PARR, de acordo com Harris (1970).

As amostras de leite foram analisadas no Laboratório de Análises de Leite e Derivados do Ministério da Agricultura, Rio de Janeiro, RJ. Foram determinados os teores de lactose, proteína bruta, gordura e energia bruta. A lactose foi determinada por titulação; o teor de gordura, utilizando-se os butirômetros de Gerber; e o teor de proteína bruta, pelo método micro-Kjeldahl, após pré-secagem das amostras de leite, segundo metodologia descrita por Wandeck et al. (1977). A energia foi estimada pela multiplicação dos teores dos constituintes do leite pelo seu valor calórico.

Os valores de produção diária de leite, de produção total durante a lactação e de composição do leite foram submetidos à análise estatística descritiva para determinação das médias e seus respectivos desviospadrão. Na avaliação da produção de leite nos períodos diurno e noturno, foi utilizado um delineamento experimental inteiramente casualizado em arranjo de parcelas subdivididas, em que a produção de leite nos períodos foi avaliada nas parcelas e os períodos de lactação, nas subparcelas. Os valores de produção de leite foram submetidos à análise de variância e os valores médios dos períodos diurno e noturno e dos grupos, divididos em função da idade, foram comparados pelo teste Tukey $(\mathrm{P}<0,05)$, utilizando-se o programa SAEG - Sistema de Análises Estatísticas e Genéticas (UFV, 2000).

A análise da regressão foi empregada para avaliar a variação dos constituintes do leite, gordura, lactose, proteína e energia, em função do período de lactação, utilizando as funções linear e quadrática do software estatístico SAEG - Sistema de Análises Estatísticas e Genéticas (UFV, 2000).

R. Bras. Zootec., v.34, n.2, p.627-634, 2005 


\section{Resultados e Discussão}

Na Tabela 2, podem ser observados os valores médios de produção de leite das éguas e respectivos desvios-padrão, expressos em $\mathrm{kg}$ de leite produzido por dia e em percentual do peso vivo das éguas. A produção de leite diária das éguas variou de $9,95 \mathrm{~kg} /$ dia na $40^{\circ}$ dia de lactação a $7,48 \mathrm{~kg} / \mathrm{dia}$ no $160^{\circ}$ dia de lactação.

Observou-se a mesma tendência quando a produção de leite foi expressa em porcentagem do peso vivo, com valores variando entre $2,3 \%$ do peso vivo no 20 o dia de lactação a 1,8\% do peso vivo no final da lactação.

A produção total de leite, obtida pelo somatório das médias de cada período multiplicadas pelo número de dias do período de lactação, foi de $1405,56 \mathrm{~kg}$.

A produção de leite observada foi semelhante à relatada em éguas Quarto de Milha por Gibbs et al. (1982), quando verificaram que a produção máxima diária ocorreu logo após o primeiro mês de lactação, com produção média diária de $11,9 \mathrm{~kg}$ de leite, e também semelhante à relatada em éguas PSI por Oftedal et al. (1983), quando verificaram que a produção máxima diária de leite ocorreu por volta do $40^{\circ}$ dia de lactação, com 17,6 kg de leite.

Alguns autores observaram que a produção máxima de leite ocorre por volta do segundo mês de lactação. Cabrera et al. (1990), avaliando éguas da raça PSI, observaram que a produção máxima de leite ocorreu logo após o segundo mês de lactação, com produção diária de $14,9 \mathrm{~kg}$ de leite, resultado seme-

Tabela 2 - Valores médios e respectivos desvios-padrão da produção de leite e do peso vivo (PV) das éguas durante a lactação

Table 2 - Average and standard deviations of milk yield and body weight $(B W)$ of mares during lactation

\begin{tabular}{cccc}
\hline $\begin{array}{c}\text { Lactação } \\
\text { (dias) } \\
\text { Lactation (days) }\end{array}$ & $\begin{array}{c}\text { PV éguas }(\mathrm{kg}) \\
\text { BW mares }\end{array}$ & \multicolumn{2}{c}{$\begin{array}{c}\text { Produção de leite } \\
\text { Milkyield }\end{array}$} \\
\cline { 3 - 4 } & & $\begin{array}{c}\text { (kg/dia) } \\
(\mathrm{kg} / \text { day })\end{array}$ & $\begin{array}{c}(\% \mathrm{PV}) \\
(\% \mathrm{BW})\end{array}$ \\
\hline 20 & $425 \pm 7,28$ & $9,66 \pm 1,11$ & 2,3 \\
40 & $427 \pm 8,40$ & $9,95 \pm 0,67$ & 2,3 \\
60 & $430 \pm 14,88$ & $9,53 \pm 0,74$ & 2,2 \\
80 & $428 \pm 15,06$ & $9,04 \pm 1,31$ & 2,1 \\
100 & $428 \pm 15,10$ & $8,61 \pm 0,99$ & 2,0 \\
120 & $429 \pm 12,94$ & $8,37 \pm 1,50$ & 1,9 \\
140 & $426 \pm 10,88$ & $7,64 \pm 1,30$ & 1,8 \\
160 & $424 \pm 10,99$ & $7,48 \pm 1,44$ & 1,8 \\
\hline
\end{tabular}

R. Bras. Zootec., v.34, n.2, p.627-634, 2005 lhante ao observado por Doreau et al. (1990), em éguas da raça Bretão Postier, quando a produção máxima ocorreu na oitava semana de lactação, com produção diária de $26 \mathrm{~kg}$ de leite. Portanto, a produção de leite de éguas decresce a partir do segundo mês de lactação, sugerindo que, após este período, pode haver déficit no fornecimento de nutrientes para os potros.

O valor médio de produção de leite, expressa em percentual do peso vivo no pico de lactação, observado nesta pesquisa $(2,3)$ foi semelhante ao citado por Pinto et al. (2001), avaliando a produção de leite de éguas sem raça definida, mantidas em pastejo e sem suplementação, de 2,4, e por Gibbs et al. (1982), de 2,1, no pico de lactação de éguas da raça Quarto de Milha.

Outros autores encontraram valores um pouco maiores - Doreau et al. (1990), de 3,0\% do PV, em éguas da raça Bretão Postier, e Cabrera et al. (1990), de 2,8\% do PV, em éguas da raça PSI. Segundo Doreau \& Boulot (1989), a metodologia descrita por Gibbs et al. (1982) pode subestimar a produção de leite, em decorrência do longo intervalo de tempo entre as mensurações (três horas). No presente trabalho, o intervalo de tempo entre mensurações foi reduzido para duas horas, visando a melhor estimativa dos valores de produção de leite.

Não houve redução $(\mathrm{P}>0,05)$ do peso vivo das éguas ao longo do período de lactação, indicando que a suplementação com $2,0 \mathrm{~kg}$ de ração concentrada por dia e o manejo dos animais nas pastagens foram suficientes para manter o peso vivo das éguas. Pinto et al. (2001) e Martin et al. (1992), em estudos realizados com éguas lactantes mantidas exclusivamente em pastagens de capim-coastcross, não verificaram perdas de peso significativas ao longo do período de lactação.

Na Tabela 3, podem ser observados os valores de produção de leite das éguas da raça Mangalarga Marchador, nos períodos diurno e noturno, não sendo encontrada diferença $(\mathrm{P}>0,01)$ entre os dois períodos durante a lactação. Esta é uma informação importante, visto ser possível desenvolver estudos de avaliação da produção de leite somente durante um dos períodos e estimar, a partir dos resultados, a produção diária de leite.

Por outro lado, há variação na produção de leite em horários específicos do dia (Figura 1). Observase redução acentuada na produção de leite das éguas nos horários mais quentes do dia, bem como durante a madrugada, em decorrência, provavelmente, da metodologia adotada ou de variáveis ambientais. 
Tabela 3 - Produção de leite das éguas da raça Mangalarga Marchador, nos horários diurno e noturno

Table 3 - Milk yield of Mangalarga Marchador mares in daytime and nighttime

\begin{tabular}{ccc}
\hline $\begin{array}{l}\text { Lactação (dias) } \\
\text { Lactation (days) }\end{array}$ & \multicolumn{2}{c}{$\begin{array}{c}\text { Produção de leite }(\mathrm{kg}) \\
\text { Milk yield }\end{array}$} \\
\cline { 2 - 3 } & $\begin{array}{c}\text { Diurno } \\
\text { Daytime }\end{array}$ & $\begin{array}{c}\text { Noturno } \\
\text { Nighttime }\end{array}$ \\
\hline 20 & 4,6 & 4,9 \\
40 & 4,7 & 5,3 \\
60 & 4,9 & 4,5 \\
80 & 4,3 & 4,7 \\
100 & 4,4 & 4,1 \\
120 & 4,1 & 4,2 \\
140 & 3,7 & 4,0 \\
160 & 3,7 & 3,7 \\
\hline CV $=14,67 \%$ & &
\end{tabular}

$\mathrm{CV}=14,67 \%$

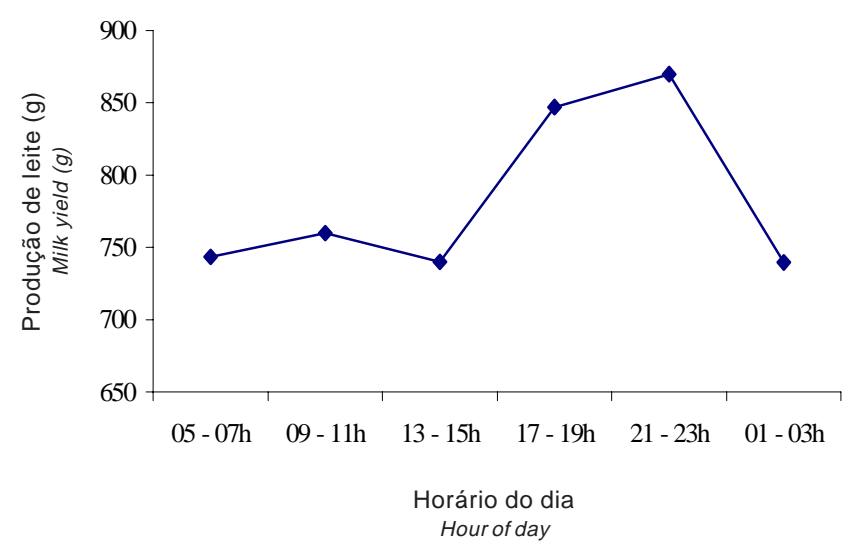

Figura 1 - Produção de leite das éguas da das éguas da raça Mangalarga Marchador, nos diversos horários do dia.

Figure 1 - Milk yield of Mangalarga Marchador mares along the day.

Na Tabela 4, podem ser observados os valores médios de produção diária de leite, em função da idade das éguas. Não houve diferença $(\mathrm{P}>0,01)$ na produção de leite entre as éguas com idade variando de 8 a 11 anos e as éguas emtre 16 e 19 anos, durante a lactação.

Constam na Tabela 5 os valores de peso vivo e ganho de peso médio diário dos potros durante o período de amamentação. Os potros nasceram com $39,38 \mathrm{~kg}$, equivalente a $9,31 \%$ do peso vivo das éguas, e aos 160 dias alcançam $163,5 \mathrm{~kg}$, equivalente a $38,52 \%$ do PV das éguas. Durante os primeiros 160
Tabela 4 - Valores médios da produção de leite de éguas da raça Mangalarga Marchador com idade entre 8 e 11 anos (Grupo-1) e entre 16 e 19 anos (Grupo-2)

Table 4 - Average of milk yield of of Mangalarga Marchador mares with age between 8-11 years (Group-1) and between 16-19 years of age (Group-1I)

\begin{tabular}{ccc}
\hline $\begin{array}{l}\text { Lactação (dias) } \\
\text { Lactation (days) }\end{array}$ & \multicolumn{2}{c}{$\begin{array}{c}\text { Produção de leite (kg) } \\
\text { Milk yield }\end{array}$} \\
\cline { 2 - 3 } & $\begin{array}{c}\text { Grupo I } \\
\text { Group I }\end{array}$ & $\begin{array}{c}\text { Grupo II } \\
\text { Group II }\end{array}$ \\
\hline 20 & 8,96 & 10,18 \\
40 & 9,83 & 10,06 \\
60 & 9,22 & 9,25 \\
80 & 8,58 & 9,48 \\
100 & 8,40 & 8,82 \\
120 & 7,91 & 8,58 \\
140 & 7,93 & 8,08 \\
160 & 7,20 & 8,30 \\
\hline
\end{tabular}

$C V=13,24 \%$

Tabela 5 - Valores médios e desvios-padrão do peso vivo dos potros (PV), de ganho de peso médio diário (GPMD) e peso vivo dos potros expresso em percentual do peso vivo das éguas, durante o período de amamentação

Table 5 - Average and standard deviation of foal's body weight (BW), daily weight gain (DWG) and body weight foals (BW) in percentage of mare's body weight, during lactation

\begin{tabular}{lccc}
\hline $\begin{array}{l}\text { Idade (dias) } \\
\text { Age (days) }\end{array}$ & $\begin{array}{c}\mathrm{PV}(\mathrm{kg}) \\
B W\end{array}$ & $\begin{array}{c}\text { GPMD }(\mathrm{kg}) \\
D W G\end{array}$ & $\begin{array}{c}\text { PV } \\
(\% \text { PV das éguas }) \\
\end{array}$ \\
& & \multicolumn{3}{c}{$B W(\%$ BW of mares $)$} \\
\hline $\begin{array}{l}\text { Nascimento } \\
\text { Birth }\end{array}$ & $39,38 \pm 8,43$ & 0,00 & 9,31 \\
20 & $58,38 \pm 7,28$ & 0,95 & 13,71 \\
40 & $72,38 \pm 8,40$ & 0,70 & 16,94 \\
60 & $87,13 \pm 14,88$ & 0,73 & 20,26 \\
80 & $104,63 \pm 15,06$ & 0,73 & 24,40 \\
100 & $119,38 \pm 15,16$ & 0,73 & 27,84 \\
120 & $134,00 \pm 12,94$ & 0,73 & 31,21 \\
140 & $147,38 \pm 10,88$ & 0,67 & 34,54 \\
160 & $163,50 \pm 10,99$ & 0,80 & 38,52 \\
\hline
\end{tabular}

dias de vida, os potros apresentaram ganho de peso total de $124 \mathrm{~kg}$. Do nascimento aos 40 dias de vida, os potros praticamente dobraram de peso, com aumento de 39,38 para $72,38 \mathrm{~kg}$ de $\mathrm{PV}$.

O ganho de peso médio diário do nascimento aos 160 dias foi de $0,77 \mathrm{~kg}$. Do nascimento aos 20 dias de vida, observou-se ganho de peso médio diário de $0,95 \mathrm{~kg}$ - o maior verificado durante o período experimental. A partir do $40^{\circ}$ dia de idade, houve redução no ganho de peso médio diário dos potros, com valores 
abaixo de $0,8 \mathrm{~kg} / \mathrm{dia}$. O maior ganho observado até os 20 dias pode ser atribuído aos maiores teores de proteína, gordura e energia do leite neste período.

Cabral et al. (2002), avaliando potros da raça Mangalarga Marchador, observaram que o ganho de peso médio diário dos potros ao longo do período total de amamentação foi muito próximo ao observado no presente trabalho, de $0,8 \mathrm{~kg} / \mathrm{dia}$. O peso vivo dos animais - expresso em percentual dos animais adultos - ao nascimento foi um pouco maior que o observado no presente trabalho, com os animais pesando 10,2\% do peso vivo dos animais adultos.

Santos et al. (2000), avaliando potros da raça Mangalarga Marchador, observaram valor de ganho de peso médio diário ao longo do período da amamentação abaixo $(0,71 \mathrm{~kg})$ do observado no presente trabalho. Resultado semelhante foi obtido por Almeida et al. (2000), que, também avaliando o desenvolvimento de potros da raça Mangalarga Marchador, observaram o peso ao nascimento dos potros inferior $(34,6 \mathrm{~kg})$ ao observado no presente trabalho equivalente a $8,0 \%$ do peso vivo dos animais adultos. O ganho de peso médio diário, ao longo do período da amamentação, foi menor que o observado no presente trabalho, de $0,72 \mathrm{~kg} /$ dia.

$\mathrm{Na}$ Tabela 6, podem ser observados os valores médios da composição do leite expressos nas concentrações de gordura, de lactose, de proteína e de energia. Os valores dos constituintes do leite analisados apresentaram resposta quadrática em função do período da lactação.
O leite de éguas apresenta teores reduzidos de gordura, de energia e de proteína e elevados de lactose. A concentração de gordura variou de $0,86 \%$ a $1,70 \%$; de lactose, de $6,76 \%$ a $7,10 \%$; de energia, de $373,30 \mathrm{kcal} / \mathrm{kg}$ a $527,46 \mathrm{kcal} / \mathrm{kg}$ de leite; e de proteína, de $1,48 \%$ a $2,46 \%$.

Pagan \& Hintz (1988), avaliando a composição do leite de éguas da raça Pônei, observaram variações nos teores de proteína bruta $(1,89 \%$ e $2,33 \%)$; de lactose $(6,57 \%$ e $6,60 \%)$ e de energia ( $425 \mathrm{kcal} / \mathrm{kg}$ e $485 \mathrm{kcal} / \mathrm{kg}$ ) semelhantes às observadas no presente experimento. Valores semelhantes também foram observados por Gibbs et al. (1982), que, avaliando a composição do leite de éguas da raça Quarto de Milha, observaram teores de $\mathrm{PB}$ e gordura variando entre $1,80 \%$ e $2,87 \%$ e entre $1,00 \%$ e $1,50 \%$, respectivamente.

Burns et al. (1992), avaliando a quantidade de energia presente no leite de éguas da raça Quarto de Milha, obtiveram concentração de energia do leite entre $336 \mathrm{kcal} / \mathrm{kg}$ e $576 \mathrm{kcal} / \mathrm{kg}$, enquanto Ulrrey et al. (1966), avaliando a composição do leite de éguas das raças Árabe e Quarto de Milha, verificaram teores de PB superiores aos observados no presente trabalho, de 2,0\% a 3,8\%. É importante salientar que os teores dos constituintes do leite, com exceção da lactose, diminuíram durante a lactação.

Variações no teor de lactose, de proteína, de gordura e de energia no leite podem ser constatadas, respectivamente, nas Figuras 2, 3, 4 e5.

Observa-se comportamento semelhante para os teores de gordura e de proteína, uma vez que houve

Tabela 6 - Valores médios e desvio-padrão da concentração de lactose, proteína, gordura e energia no leite durante a lactação

Table 6 - Average and standard deviations of levels of lactose, protein, fat and energy in milk during lactation

\begin{tabular}{|c|c|c|c|c|}
\hline $\begin{array}{l}\text { Lactação (dias) } \\
\text { Lactation (days) }\end{array}$ & $\begin{array}{c}\text { Lactose }^{1}(\%) \\
\text { Lactose }\end{array}$ & $\begin{array}{c}\text { Proteína }{ }^{2}(\%) \\
\text { Protein }\end{array}$ & $\begin{array}{c}\text { Gordura }^{3}(\%) \\
\text { Fat }\end{array}$ & $\begin{array}{c}\text { Energia }^{4}(\mathrm{kcal} / \mathrm{kg}) \\
\text { Energy }\end{array}$ \\
\hline 20 & $6,60 \pm 0,91$ & $2,40 \pm 0,27$ & $1,70 \pm 0,73$ & $520,68 \pm 108,9$ \\
\hline 40 & $7,10 \pm 0,10$ & $2,18 \pm 0,39$ & $1,20 \pm 0,28$ & $489,95 \pm 46,03$ \\
\hline 60 & $6,86 \pm 0,30$ & $1,84 \pm 0,63$ & $1,15 \pm 0,30$ & $457,95 \pm 67,63$ \\
\hline 80 & $6,92 \pm 0,31$ & $1,69 \pm 0,19$ & $1,00 \pm 0,35$ & $441,77 \pm 49,76$ \\
\hline 100 & $6,39 \pm 0,28$ & $1,67 \pm 0,39$ & $0,94 \pm 0,18$ & $415,13 \pm 41,34$ \\
\hline 120 & $6,40 \pm 0,34$ & $1,64 \pm 0,33$ & $0,92 \pm 0,11$ & $414,11 \pm 40,80$ \\
\hline 140 & $6,36 \pm 0,37$ & $1,61 \pm 0,43$ & $0,91 \pm 0,23$ & $408,05 \pm 55,75$ \\
\hline 160 & $5,86 \pm 0,67$ & $1,48 \pm 0,30$ & $0,86 \pm 0,37$ & $377,14 \pm 72,71$ \\
\hline
\end{tabular}

\footnotetext{
${ }^{1} \mathrm{Y}=6,6348+0,008711^{*} X-0,00008408^{*} X^{2} R^{2}=0,80$

${ }^{2} Y=2,6759-0,01584^{\star} X+0,00005521^{*} X^{2} \quad R^{2}=0,95$.

${ }^{3} \mathrm{Y}=1,885-0,01584^{\star} X+0,00006131^{*} X^{2} \quad R^{2}=0,92$.

${ }^{4} \mathrm{Y}=554,359-1,7423^{*} X+0,004331^{*} X^{2} \quad R^{2}=0,97$.
}

\section{R. Bras. Zootec., v.34, n.2, p.627-634, 2005}




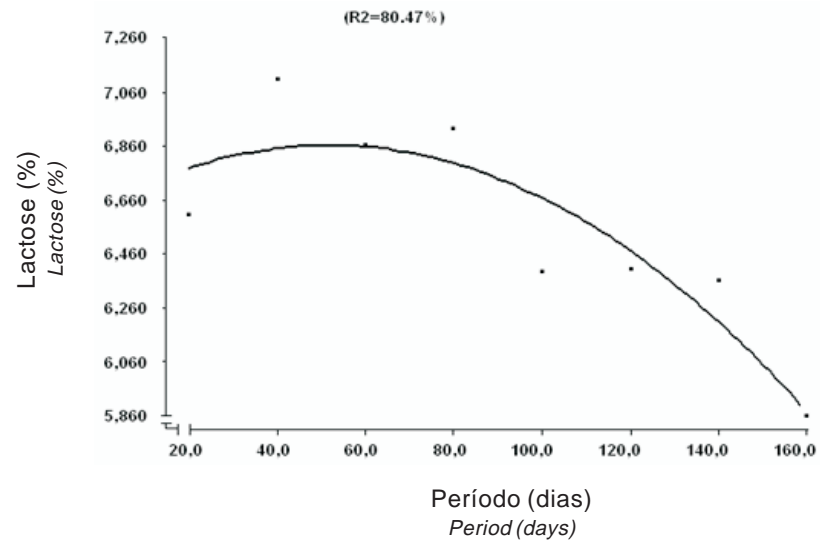

Figura 2 - Teor de lactose no leite de éguas Mangalarga Marchador durante a lactação.

Figure 2 - Milk lactose concentration of Mangalarga Marchador mares during lactation.

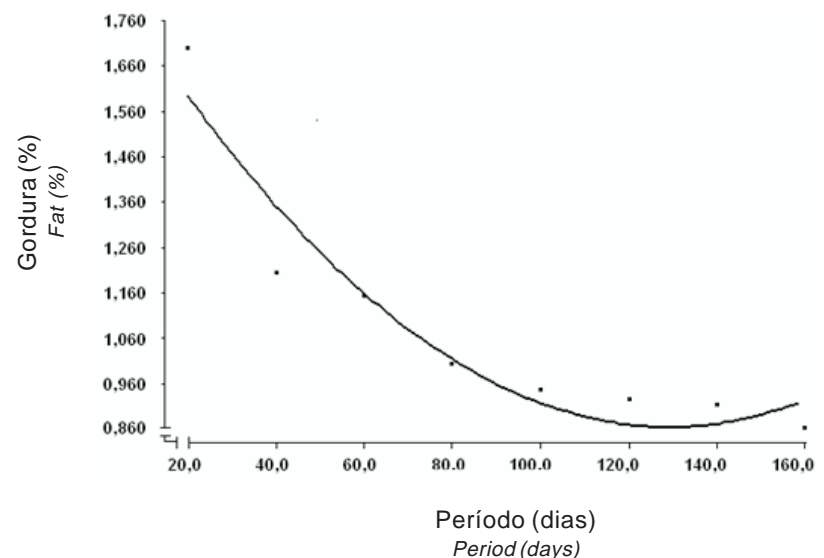

Figura 4 - Teor de gordura no leite de éguas Mangalarga Marchador durante a lactação.

Figure 4 - Milk fat concentration of Mangalarga Marchador mares during lactation.

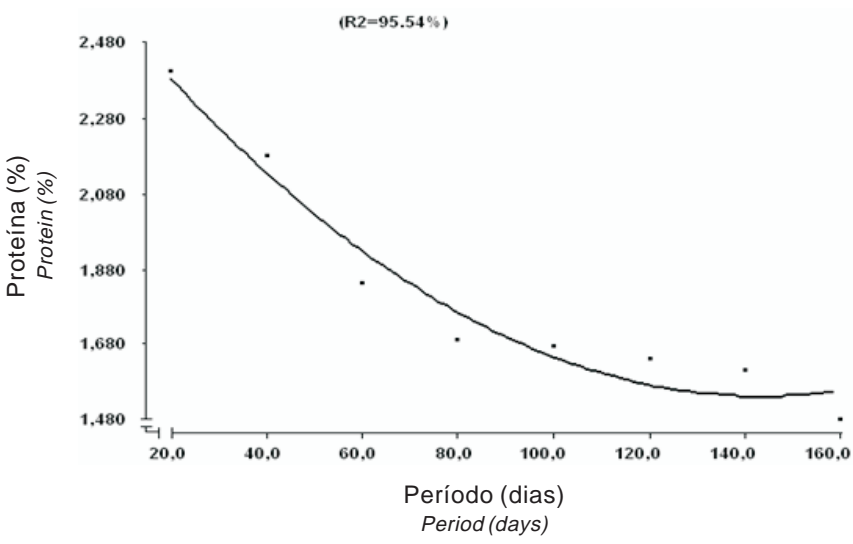

Figura 3 - Teor de proteína no leite de éguas Mangalarga Marchador durante a lactação.

Figure 3 - Milk protein concentration of Mangalarga Marchador mares during lactation.

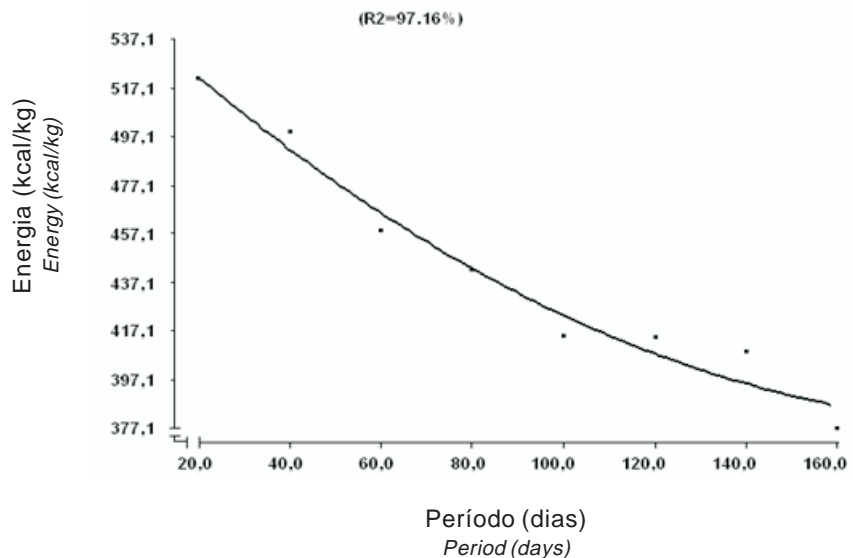

Figura 5 - Teor de energia no leite de éguas Mangalarga Marchador durante a lactação.

Figure 5 - Milk energy concentration of Mangalarga Marchador mares during lactation. 
queda brusca do $20^{\circ}$ para o $80^{\circ}$ dia de lactação, quando o declínio é mais lento até o 140 o dia de lactação.

Verificou-se aumento no teor de lactose do $20^{\text {o }}$ para o $40^{\circ}$ dia de lactação, quando passa a declinar em tendência quase linear até o $160^{0}$ dia de lactação.

Houve queda brusca, praticamente linear, no teor de energia do $20^{\circ}$ para o $100^{\circ}$ dia de lactação, quando passa a declinar mais lentamente até o $160^{\circ}$ dia de lactação.

\section{Conclusões}

A produção de leite das éguas Mangalarga Marchador avaliadas neste estudo seguem o mesmo padrão das demais raças da espécie eqüina, crescente até o segundo mês da lactação e decrescente até o término da lactação.

Futuros trabalhos podem ser conduzidos utilizando-se a metodologia da estimativa da produção de leite no período diurno, visto que não houve diferença na produção de leite entre os dois períodos estudados.

Os constituintes do leite: lactose, proteína, gordura e energia não supriram as exigências nutricionais dos potros, o que se comprova nos ganhos de peso decrescentes, ao longo do período de amamentação.

\section{Literatura Citada}

ALMEIDA, F.Q.; BRITO, C.O.; SANTOS, E.M. et al. Crescimento de potros da raça Mangalarga Marchador. In: REUNIÃO ANUAL DA SOCIEDADE BRASILEIRA DEZOOTECNIA, 38., 2000, Viçosa, MG. Anais... Viçosa, MG: Sociedade Brasileira de Zootecnia, 1999. p.1-3.

ASSOCIATION OF OFFICIAL ANALYTICAL CHEMISTS AOAC. Official methods of analysis. 14.ed. Washington, D.C.: 1984. 141p.

BURNS, H.D.; GIBBS, P.G.; POTTER, G.D. Milk energy production by lactating mares. Journal Equine Veterinary Science, v.10, n.2, 118-120, 1992.

CABRAL, G.C.; PINTO, L.F.B.; ALMEIDA, F.Q. et al. Avaliação morfológica de potros lactentes da raça Mangalarga Marchador: medidas lineares e angulares. In: REUNIÃO ANUAL DA SOCIEDADE BRASILEIRA DE ZOOTECNIA, 40., 2002, Recife. Anais... Recife: Sociedade Brasileira de Zootecnia, 2002. CD ROM.

CABRERA, L.; FERNANDES, L.C.; MORAES, C.M.M. Composição de leite de éguas PSI e desenvolvimento ponderal de suas crias. A Hora Veterinária, v.10, n.55, 1990.

CUNHA, T.J. Horse feeding and nutrition. 2.ed. San Diego: Academic Press, 1991. 445p.

DOREAU, M.; BOLOUT, S.; MARTIN-ROSSET, W. Effect of parity and physiological state on intake, milk production and blood parameters in lactating mares differing in body size. Animal Production, v.53, p. 111-118, 1991a.
DOREAU, M.; BOULOT, S. Recent knowledge on mare milk production: a review. Livestock Production Science, v.22, p.213-235, 1989.

DOREAU, M.; BOULOT, S.; BAUCHART,D. et al. Yield and composition of milk from lactating mares: effect of lactation stage and individual differences. Journal of Dairy Research, v.57, p.449-454, 1990.

DOREAU, M.; BOULOT, S.; BAUCHART,D. et al. Voluntary intake, milk production and plasma metabolites in nursing mares fed two different diets. Journal of Nutrition, v.122, p.992-999, 1991b.

GIBBS, P.G.; POTTER, G.D.; BLAKE, R.W. et al. Milk production of Quarter horse during 150 days of lactation. Journal of Animal Science, v.54, n.3, p.497-450, 1982.

HARRIS, L. E. Os métodos químicos e bioquímicos empregados na análise de alimentos. Gainesville: Universidade da Flórida, 1970. Paginação discontinuada.

HENNEKE, D.R.; POTTER, G.D.; KREIDER, J.L.; YEATES, B.F. Relationship between condition score, physical measurements and body fat percentage in mares. Equine Veterinary Journal, v.15, n.4, p.897-903, 1983.

MARTIN, R.G.; McMENIMAN, N.P.; DOWSETT, K.F. Milk and water intakes of foals sucking grazing mares. Equine Veterinary Journal, v.24, n.4, p.295-299, 1992.

OFTEDAL, B.O.T.; JENNESS, R. Interspecies variation in milk composition among horses, zebras and asses. Journal of Dairy Research, v.56, p.57-66, 1988.

OFTEDAL, O.T.; HINTZ, H.F.; SCHRYVER, H.F. Lactation in the horse: milk composition and intake by foals. Journal Nutrition, v.113, p.2196-2206, 1983.

PAGAN, J.D.; HINTZ, H.F. Composition of milk from pony mares fed various levels of digestible energy. Cornell Veterinarian, v.76, n.2, p.139-148. 1988.

PINTO, C.M.D.; OLIVEIRA, K.; SENO, L.O. et al. Avaliação do desempenho de éguas a pasto em diferentes estádios de lactação. In: REUNIÃO ANUAL DA SOCIEDADE BRASILEIRA DE ZOOTECNIA, 39., 2001, Piracicaba. Anais... Piracicaba: Sociedade Brasileira de Zootecnia, 2001. CD ROM

SAASTAMOINEN, M.T. Serum urea and protein concentrations and growing rates of weanling foals. Pferdeheikunde, v.12,n.3, p.323-325, 1996.

SANTOS, E.M.; LOPES, B.A.; CORASSA, A. et al. Estudo biométrico de potros lactentes da raça Mangalarga Marchador. In: JORNADA DE INICIAÇÃO CIENTÍFICA DA UFRRJ, 2000, 10., Seropédica. Anais... Seropédica: Universidade Federal Rural do Rio de Janeiro, 2000. p.183-184.

ULRREY, D.E.; STRUTHERS, R.D.; HENDRICKIS, D.G. et al. Composition of mares' milk. Journal of Animal Science, v.25, n.1, p.217-221, 1966.

UNIVERSIDADEFEDERALDE VIÇOSA - UFV. SAEG - Sistema de análises estatísticas e genéticas. Viçosa, MG. (Software v.8.0). 2000.

WANDECK, F.A.; BARROS, G.C.; MATTOS NETO, P.J. et al. Análise de leite e derivados. 1.ed. Rio de Janeiro: Universidade Federal Rural do Rio de Janeiro, 1977. 143p.

Recebido em: 05/05/03 Aceito em: 08/09/04 